\title{
Participation of Wind Power Producers in Intra-day Markets: A Case Study
}

\author{
Tomás Rocha ${ }^{1}$, Hugo Algarvio ${ }^{2,3}$, Fernando Lopes $^{2}$, \\ Anabela Pronto ${ }^{1}$, João Santana ${ }^{3,4, \star}$ \\ 1 Faculdade de Ciências e Tecnologia, Universidade Nova de Lisboa, Portugal \\ tg.rocha@campus.fct.unl.pt, amg1@fct.unl.pt \\ 2 LNEG-National Research Institute, Est. Paço do Lumiar 22, Lisboa, Portugal \\ fernando.lopes@lneg.pt \\ 3 Instituto Superior Técnico, Avenida Rovisco Pais 1, Lisboa, Portugal \\ \{hugo.algarvio, jsantana\}@tecnico.ulisboa.pt \\ 4 INESC-ID, Rua Alves Redol 9, Lisboa, Portugal
}

\begin{abstract}
The evolution of renewable energy has increased substantially over the past decade. Wind power producers (WPPs) can submit bids to energy markets, making short-term commitments to produce specific quantities of energy. This article presents a study to investigate the active participation of wind power producers in energy markets, particularly intra-day markets. The study is carried out with the help of the MATREM system. The results indicate a reduction of the deviations of WPPs, but also a decreasing in their remuneration. Thus, the results highlight to some extent the importance of new market mechanisms to enable the active participation of WPPs in markets, without incentive policies.
\end{abstract}

Keywords: Electricity markets, variable renewable energy, wind power producers, intra-day markets, MATREM system.

\section{Introduction}

Electricity markets are a complex evolving reality - there is now a significant number of market participants, each one with their own set of objectives and strategies $[1,2]$. In Europe, day-ahead markets (DAMs) are the most liquid markets, closing at 12:00 p.m., and using EUPHEMIA, an algorithm based on the marginal pricing theory (see, e.g., [3]). Intraday markets (IDMs) may consider auctions or operate continuously. Forward markets trade bilateral contracts to hedge against pool price volatility. Balancing markets (BMs) allow to compensate deviations from the programming schedules committed in other markets.

\footnotetext{
* This work was supported by "Fundação para a Ciência e Tecnologia" with reference UID/CEC/50021/2019.
} 
Most existing market designs were developed without considering the active participation of wind power producers and variable renewable energy (VRE) producers generally. Recently, the European Commission published new rules that establish the general principles and technical details on energy market participation, as well as specify rights and responsibilities among market participants $[4,5]$. The new rules touch upon a variety of technical aspects, including short term markets, more efficient dispatch, removal of price caps, and a better demand participation. Also, day-ahead and intra-day markets should be organized as being non-discriminatory, transparent, and mainly ensuring that all participants will be able to access the market individually or through aggregation. By 1 January 2021, the imbalance settlement period shall be 15 minutes in all scheduling areas. Balancing markets should respect the need to accommodate the increasing share of variable generation and the advent of new technologies. Market participants shall be allowed to bid as close to real time as possible, and balancing energy gate closure times shall not be before the intra-day cross-zonal gate closure time.

High shares of variable generation lead typically to a decrease in market prices $[6,7]$. Intra-day markets have low liquidity in the majority of the European countries, probably because they are not the only option to trade electricity in a particular period of time. Continuous intra-day markets seem to be not very attractive (or even adequate) to the participation of VRE producers, since the variable cost of these producers is near-zero, and thus they will trade energy at very low prices in these markets. However, intra-day markets based on auctions, with several sessions, such as the Iberian market (MIBEL), are markets with a relative high liquidity. Accordingly, this paper presents a study to investigate the active participation of wind power producers (WPPs) in intra-day markets. The study is conducted with the help of an agent-based tool, called MATREM $[8,9]$. It considers seven energy scenarios involving the participation of WPPs in the day-ahead market and mainly in different session of the intra-day market. Also, it consider data from the Iberian market and REN (The Portuguese Transmission System Operator, responsible for operating the National balancing market).

The work presented here builds on our previous work in the areas of market design and the trade of wind power in energy markets $[10,11]$. In [10], we investigated the benefits of the participation of wind power producers in day-ahead and balancing markets. In [11], we analyzed the impact of the forecast uncertainty and the day-ahead market gate closure on market prices, price volatility and balancing reserve requirements. In this paper, as noted, we investigate the benefits of the participation of WPPS in intra-day markets, in terms of the deviations in reductions and the final revenue.

The remainder of the paper is structured as follows. Section 2 presents a brief overview of electricity markets. Section 3 describes the strategic behavior of wind producers in energy markets. Section 4 presents an overview of the markets supported by the MATREM system. Section 5 presents the case-study and discusses the experimental results. Finally, concluding remarks are presented in section 6 . 


\section{Electricity Markets}

The main European markets include the Nordic market (Nordpool), the European central market (EPEX) and the Iberian market (MIBEL). The trading occurs in day-ahead markets through implicit auctions, where clearing prices and equilibrium quantities are computed for every hour of the next day, using the system marginal pricing theory. Intra-day markets may involve auctions, like DAMs, but with several sessions, or can operate continuously, using the pay-asbid scheme and bilateral contracts.

Transmission system operators consider the commitments made in DAMs and IDMs, and the deviations should be balanced in the balancing markets. There are three key types of load-frequency control products negotiated in European BMs. During real-time operation, primary or frequency controlled reserve (FCR) is the first product to be activated. Secondary or automatic-activated frequency restoration reserve (aFRR) should be activated in 30 seconds, taking a maximum of 15 minutes to be completed, replacing FCR. Tertiary or manually-activated FRR (mFRR) should be fully activated in 15 minutes, and can continue active for hours, freeing up FCR and aFRR.

Forward markets are commonly used to hedge against pool price volatility. However, if derivative products are inappropriately chosen, they may actually reduce the benefit, since market-clearing prices may end up being either too high or too low when compared with contracted prices. Customized (or tailored) forward contracts are essentially long-term contracts, designed to cover the delivery of large amounts of power over longs periods of time.

The participants in electricity markets are heterogeneous and autonomous, and typically follow their own goals and negotiation strategies. Production companies seek to adopt strategies that maximize profit, while consumers adopt strategies that minimize the electricity cost. Also, retailers seek to maximize profit by selling energy to customers. Profit margins are usually narrow as retailers should provide their clients with the lowest possible prices to avoid them to change supplier.

\section{Participation of Wind Power Producers in Markets}

Wind power producers can submit (wind power) forecasts to the day-ahead market during day $d-1$, thus making commitments to produce specific quantities of wind energy during day $d$. They can also submit bids to the intra-day market, which are essentially deviations, computed by taking into account the commitments previously made and the updates of wind power forecasts.

WPPs can adopt a strategic behavior to "optimize" their deviations. In the case of large excess deviations from the DAM commitments, it may be favourable to bid such deviations in the intra-day market. Concretely, WPPS can submit the excess deviations from the DAM commitments to the intra-day market at a price near $0 € / M W h$, thus receiving the clearing price (instead of paying penalties by participating in BMs). This strategic behaviour is essentially a deviationreduction behaviour, not a profit-seeking one. 
Accordingly, the following seven scenarios are considered in this work (see also Section 5):

- Baseline: wind power producers participate in the day-ahead market only;

- S1: WPPs participate in the DAM and the IDM (2nd session: 0-6 h, 3rd session: 6-12 h, 4th session: 12-18 h, and 5th session: 18-24 h);

- S2: WPPs participate in the DAM and IDM (2nd session: 0-6 h, 3rd session: 6-12 $\mathrm{h}$ and 4th session: 12-24 h);

- S3: WPPs participate in the DAM and the IDM (2nd session: 0-6 h, 3rd session: $6-18 \mathrm{~h}$ and 4th session: 18-24 h);

- S4: WPPs participate in the DAM and the IDM (2nd session: 0-12 h, and 4th session: $12-24 \mathrm{~h}$ );

- S5: WPPs participate in the DAM and the IDM (2nd session: 0-18 h, and 5th session: $18-24 \mathrm{~h}$ );

- S6: WPPs participate in the DAM and the IDM (2nd session: 0-24 h).

\section{MATREM: Overview of the Supported Markets}

MATREM (for Multi-Agent TRading in Electricity Markets) is an agent-based simulation tool for analyzing the behavior and outcomes of electricity markets. The tool supports a day-ahead market, an intra-day market, a balancing market, and a futures market. It also supports a marketplace for negotiating tailored (or customized) bilateral contracts. A detailed description of the system is presented in [8]. A classification of the system according to various dimensions associated with both electricity markets and intelligent agents can be found in [9].

The day-ahead market is a central market where generation and demand can be traded on an hourly basis [12]. The intra-day market is a short-term market and involves several auction sessions. It is used to make adjustments in the positions of participants as delivery time approaches. Both the day-ahead and the intra-day markets are based on the marginal pricing theory. Two pricing mechanisms are supported: system marginal pricing and locational marginal pricing.

The balancing market is a market for primary reserve (or frequency control reserve), secondary reserve (or fast active disturbance reserve), and tertiary reserve (or slow active disturbance reserve). The futures market is an organized market for both financial and physical products conditioned on delivery at a specific time and place. Such products may span from days to years and typically hedge against the financial risk (i.e., price volatility) inherent to day-ahead and intra-day markets.

Especially noteworthy is the possibility to negotiate tailored (or customized) long-term bilateral contracts, specifically forward contracts and contracts for difference (see, e.g., [13]). The terms and conditions of such contracts are flexible and can be negotiated privately to meet the objectives of two parties. To this end, market agents are equipped with a model that handles two-party and multi-issue negotiation. The negotiation process involves basically and iterative exchange of proposals and counter-proposals $[14,15]$. 
Table 1. Key features of the producer agents.

\begin{tabular}{lllll}
\hline Agent & Country & Type & $\begin{array}{l}\text { Maximum } \\
\text { Capacity } \\
(\mathrm{MW})\end{array}$ & $\begin{array}{l}\text { Marginal } \\
\text { Cost } \\
(€ / \mathrm{MWh})\end{array}$ \\
\hline$P_{1}$ & Portugal & Wind Aggregator & 2490 & 0 \\
$P_{2}$ & Portugal & Renewable mix & 2000 & 0 \\
$P_{3}$ & Spain & Renewable mix & 30000 & 0 \\
$P_{4}$ & Spain & Nuclear & 7500 & $\approx 35$ \\
$P_{5}$ & Portugal & Hydroelectricity & 4500 & {$[30 ; 60]$} \\
$P_{6}$ & Portugal & Coal & 1800 & $\approx 30$ \\
$P_{7}$ & Portugal & Combined Cycled Gas 3000 & $\approx 100$ \\
$P_{8}$ & Portugal & Fuel oil & 2000 & $\approx 170$ \\
$P_{9}$ & Spain & Hydroelectricity & 16500 & {$[30 ; 60]$} \\
$P_{10}$ & Spain & Coal & 10000 & $\approx 30$ \\
$P_{11}$ & Spain & Combined Cycled Gas 22000 & $\approx 100$ \\
$P_{12}$ & Spain & Fuel oil & 4000 & $\approx 170$ \\
\hline
\end{tabular}

Market entities are modeled as software agents equipped with models of individual and social behaviour, enabling them to be pro-active (i.e., capable of exhibiting goal-directed behaviour) and social (i.e., able to communicate and negotiate with other agents in order to complete their design objectives). The system supports generating companies, retailers, aggregators, coalitions of consumers, traditional consumers, market operators and system operators.

\section{A Case-study on the Iberian Market}

This section presents a case-study to investigate the potential benefits of the participation of wind power producers in the intra-day market. The time period of the study ranges from January 1, 2009 to December 31, 2010. To reduce the number of computational simulations, 31 representative days are selected according to a K-medoids clustering algorithm [16]). The average wind power penetration in Portugal was $16.18 \%$.

The agents are 12 producers (representing the supply-side) and four retailers (representing the demand-side). Several key features of the producer agents are shown in Table 1, including the maximum capacity of the producer P1, representing the aggregator of wind power producers, and the corresponding energy price to submit to the day-ahead market. ${ }^{5}$

The wind power generation data was achieved from a set of eight distributed WPPs situated in Portugal (involving the installed capacity of 249 MW, around $10 \%$ of the Portuguese installed capacity). To get meaningful results, the data is scaled to $2490 \mathrm{MW}$ (of installed capacity), by multiplying all values by a constant factor.

${ }^{5}$ Agent $P_{1}$ results from the aggregation of eight WPPs situated in the center of Portugal (henceforth, each WPP is referred to as $W P P_{j}, \mathrm{j}=1, \ldots, 8$ ) 
Table 2. Deviations and remuneration of the wind aggregator agent.

\begin{tabular}{cccc}
\hline $\begin{array}{c}\text { Energy } \\
\text { scenario }\end{array}$ & $\begin{array}{c}\text { Average deviation } \\
(\mathrm{MWh})\end{array}$ & $\begin{array}{c}\text { Reduction in } \\
\text { deviation }(\%)\end{array}$ & $\begin{array}{c}\text { Remuneration } \\
(€ / \mathrm{MWh})\end{array}$ \\
\hline Baseline & 322.83 & $0 \%$ & 32.87 \\
1 & 211.20 & $35 \%$ & 32.04 \\
2 & 226.62 & $30 \%$ & \\
3 & 226.32 & $30 \%$ & \\
4 & 232.11 & $28 \%$ & \\
5 & 246.91 & $24 \%$ & \\
6 & 271.42 & $16 \%$ & 32.64 \\
\hline
\end{tabular}

The following sources of data are considered in the analysis: (i) hourly prices and quantities submitted to the day-ahead and intra-day Iberian markets [17], (ii) hourly requirements of the Portuguese mFRR market, and (iii) hourly imbalances and prices of the imbalances (data reported by REN, the Portuguese Transmission System Operator [18]).

The day-ahead and intra-day Iberian markets are simulated by using the MATREM system. The results are presented in Table 2 and Figs. 13. Specifically, Table 2 presents the reductions in the deviations of the wind aggregator by considering the seven aforementioned energy scenarios. The baseline scenario involves no deviations, since the wind aggregator participates in the DAM only. Scenario S1 presents slightly better results (in terms of deviations) than scenarios S2 and S3, which in turn present better results than scenarios S4, S5 and S6. Figure 1 presents the results for the 31 representative days by considering the baseline and the S1 scenarios. For the majority of days, scenario S1 results in a reduction of the deviations.

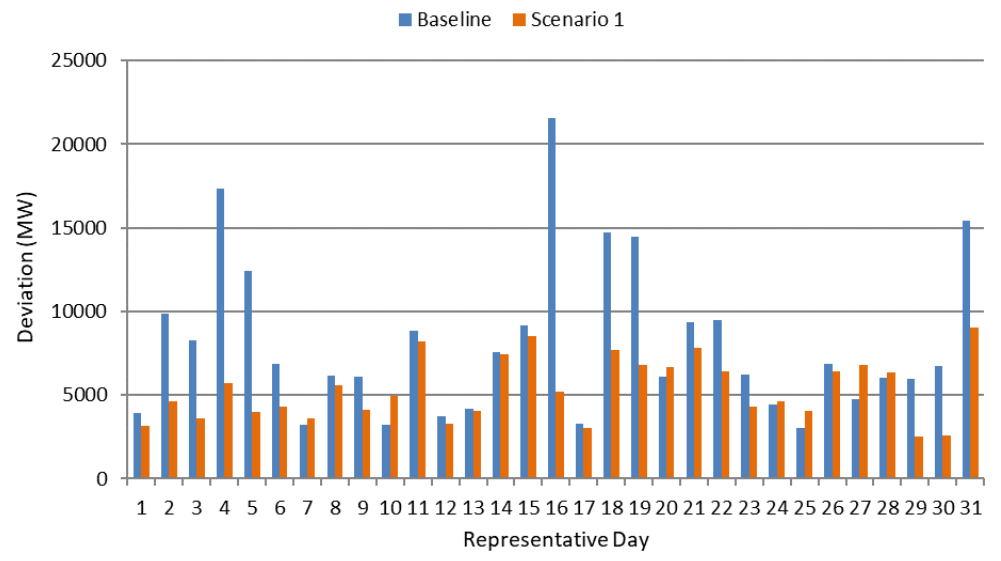

Fig. 1. Baseline and scenario S1: deviations in the 31 representative days 


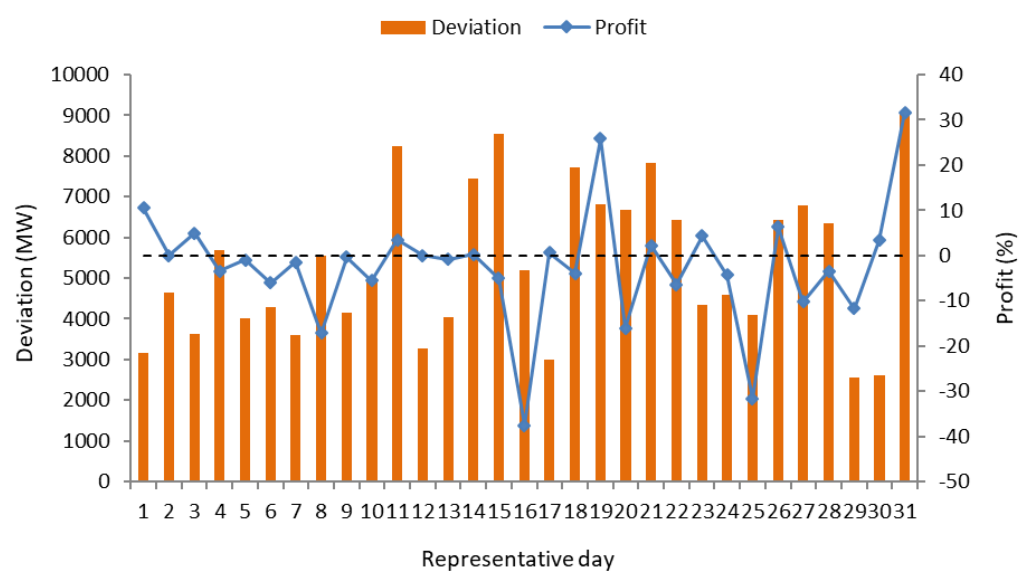

Fig. 2. Scenario S1: profit of the wind aggregator (in relation to the baseline).

Figure 2 presents the relative profit of the wind aggregator in scenario S1 (when compared with the baseline). In most of the 31 representative days, the profit is "negative" (i.e., below the reference profit). A possible explanation is as follows: a significant share of wind power in the intra-day market results in a decrease of the market-clearing price, thus reducing the remuneration of the wind producers. This is a direct effect of the lack of liquidity of the intra-day market, since the marginal technology in certain periods of time is a technology with a (very) low marginal cost.

Figure 2 also presents the deviations of the wind aggregator agent. Apparently, there is not an evident correlation between the deviations and the profit of this agent. Probably, this happens because of the bids that the wind aggregator submits to the intra-day market - that is, bids based on forecast updates when an excess of energy is predicted (in relation to the day-ahead commitments).

Figure 3 depicts the profit of the wind aggregator in scenario S1 (when compared with the baseline) and the bids submitted to the intra-day market. As shown in the Figure, when the bids are significant, the remuneration of the wind aggregator decreases. Overall, the actual intra-day market seems to be not a very attractive option for the participation of wind power producers.

\section{Conclusion}

Variable renewable energy producers represent a significant source of deviations in energy markets. Mechanisms that incentivize the participation of VRE producers in markets without considering feed-in-tariffs or other incentive policies are important to increase the efficiency and reliability of power systems. 


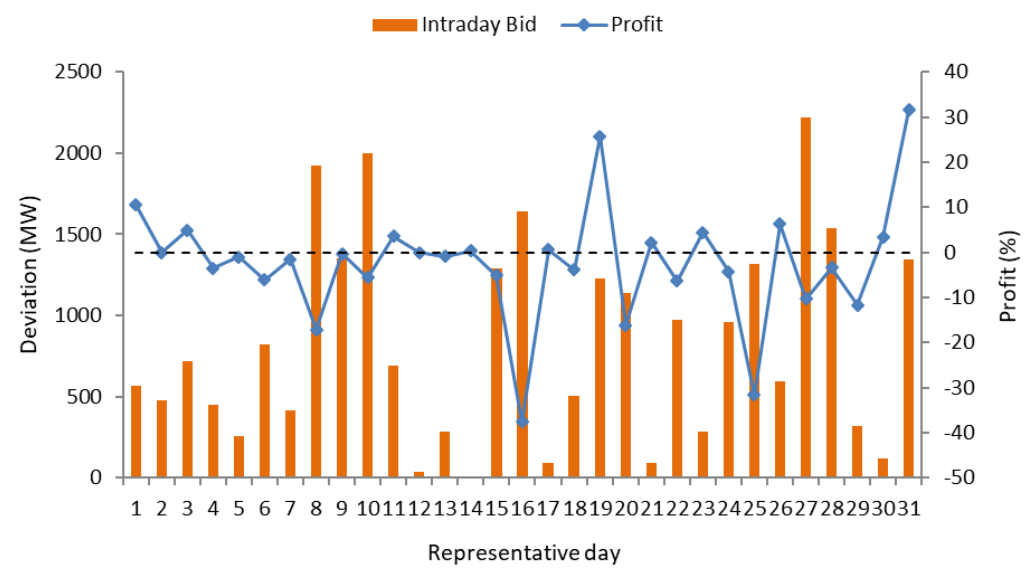

Fig. 3. Scenario S1: relative profit and bids submitted to the intra-day market.

At present, intra-day markets based on auctions are markets where VRE producers can submit bids to reduce the deviations arising from forecast errors. Accordingly, this paper presented a study on the active participation of wind power producers in the Iberian market. The study involved seven scenarios where wind power producers may participate in the day-ahead and intra-day markets. The results allow to conclude that the participation of a wind aggregator in these markets, mainly in the intra-day market, lead to a reduction in the forecast deviations, but also in the final remuneration. Thus, the results highlight the importance of new market mechanisms to enable the active participation of VRE in electricity markets without incentives.

\section{References}

1. Lopes, F., Coelho, H.: Electricity Markets with Increasing Levels of Renewable Generation: Structure, Operation, Agent-based Simulation and Emerging Designs, Springer, Cham, 2018. https://doi.org/10.1007/978-3-319-74263-2

2. Kirschen, D., Strbac, G.: Fundamentals of Power System Economics, John Wiley \& Sons, Chichester, 2018.

3. Sleisz, A., Sores, P., Raisz, D.: Algorithmic Properties of the all-European Dayahead Electricity Market, In: 11th International Conference on the European Energy Market (EEM), pp. 1-5, IEEE Computer Society, 2014.

4. European Commission, Regulation (EU) 2019/943 of the European parliament and of the Council on the Internal Market for Electricity, 5 June 2019. Availabe at: http://data.europa.eu/eli/reg/2019/943/oj (access date: February 2020)

5. European Commission, Common Rules for the Internal Market for Electricity (amending Directive 2012/27/EU), Directive 2019/944, 5 June 2019. Available at: http://data.europa.eu/eli/dir/2019/944/oj (access date: February 2020).

6. Azofra, D., Martínez, E., Jiménez, E., Blanco, J., Azofra, F., Saenz-Díez, J.: Comparison of the Influence of Photovoltaic and Wind Power on the Spanish 
Electricity Prices by Means of Artificial Intelligence Techniques. Renewable and Sustainable Energy Reviews 42, pp. 532-542, 2015.

7. Ela, E., Milligan, M., Bloom, A., Cochran, J., Botterud, A., Townsend, A., Levin, T.: Overview of Wholesale Electricity Markets, In: Electricity Markets with Increasing Levels of Renewable Generation: Structure, Operation, AgentBased Simulation and Emerging Designs, Springer International Publishing, Cham, Switzerland, pp. 3-21, 2018.

8. Lopes, F.: MATREM: An Agent-based Simulation Tool for Electricity Markets., In: Electricity Markets with Increasing Levels of Renewable Generation: Structure, Operation, Agent-Based Simulation and Emerging Designs, Springer, Cham, Switzerland, pp. 189-225, 2018.

9. Lopes, F., Coelho, H.: Electricity Markets and Intelligent Agents. Part II: Agent Architectures and Capabilities, In: Electricity Markets with Increasing Levels of Renewable Generation: Structure, Operation, Agent-Based Simulation and Emerging Designs, Springer, Cham, Switzerland, pp. 49-77, 2018;

10. Algarvio, H., Lopes, F., Couto, A., Estanqueiro, A.: Participation of Wind Power Producers in Day-ahead and Balancing Markets: An Overview and a Simulationbased Study. WIREs Energy and Environment, 8(5):e343, 2019.

11. Algarvio, H., Couto, A., Lopes, F., Estanqueiro, A.: Changing the Day-Ahead Gate Closure to Wind Power Integration: A Simulation-Based Study, Energies 12(14):2765, 2019.

12. Vidigal, D., Lopes, F., Pronto, A., Santana, J.: Agent-based Simulation of Wholesale Energy Markets: a Case Study on Renewable Generation, In: Spies, M., Wagner, R., Tjoa, A. (eds.), 26th Database and Expert Systems Applications (DEXA 2015), pp. 81-85, IEEE, 2015.

13. Sousa, F. Lopes, F., Santana, J.: Contracts for Difference and Risk Management in Multi-agent Energy Markets, In: Advances in Practical Applications of Agents, Multi-Agent Systems, and Sustainability: The PAAMS Collection (PAAMS 2015), Springer International Publishing, pp. 339-347, 2015.

14. Lopes, F., Mamede, N., Novais, A. Q., Coelho, H.: A Negotiation Model for Autonomous Computational Agents: Formal Description and Empirical Evaluation, Journal of Intelligent \& Fuzzy Systems 12, pp. 195-212, 2002.

15. Lopes, F., Mamede, N., Novais, A. Q., Coelho, H.: Negotiation in a Multi-Agent Supply Chain System, In: 3rd Int. Workshop of the IFIP WG 5.7 Special Interest Group on "Advanced Techniques in Production Planning \& Control", pp. 153-168, Firenze University Press, 2002.

16. Park, H., Jun, C.: A simple and fast algorithm for K-medoids clustering, Expert Systems Applications, 36 (2), pp. 3336-3341, 2009.

17. OMIE: "Operador del Mercado Ibérico de Energía (Spanish Electricity Market Operator)." Market Results (online data)

Availabel at: http://www.omie.es/files/flash/ResultadosMercado.swf (Cited on 22 February, 2020)

18. REN: Redes Energéticas Nacionais, Daily Summary. Available at: http://www.centrodeinformacao.ren.pt/PT/InformacaoExploracao/Paginas/EstatisticaDiariaDiagrama.aspx (Cited on 22 February, 2020) 